\title{
You say tomato
}

\author{
Alan McHughen
}

First Fruit: The Creation of the Flavr Savr Tomato and the Birth of Biotech Food By Belinda Martineau

McGraw Hill; \$24.95, 269 pp, hardcover ISBN 0071360565, 2001

Belinda Martineau is a scientist, a writer, and a citizen concerned about health and the state of the environment. In First Fruit, Martineau, as a staff scientist working for the biotechnology startup Calgene (Davis, CA), provides an inside view of the development of the Flavr Savr tomato, the first genetically engineered whole food to reach the US marketplace. There are several stories intertwined through the pages, each one interesting in its own way.

The story of the rise and fall of Calgene is a major strand, and Martineau keeps our attention with a series of interesting vignettes. Venture capital elicited not with a product, but with the mere concept of a potential commercial product. Unrealistic technical and production schedules. Intellectual property turf battles. Regulatory approvals. Laboratory and field trials. Scaleup and marketing. Consumer demand exceeding production capacity. And then the boom falls as Monsanto (St. Louis, $\mathrm{MO})$ closes in.

Martineau maintains a lively flow of the ups and downs faced by Calgene (and likely by most small biotech startups) in their attempt to create a product and put it on the market. These include not only the scientific hurdles, like cloning the gene and inserting it into the plant, or figuring out a satisfactory method to measure fruit firmness, but also the exciting race to the patent office. For scientists, one of the most alien (but important) threads is the coverage of the several patent disputes and reliance on laboratory notes to

Alan McHughen is a professor and senior research scientist at the University of Saskatchewan(mchughen@duke.usask.ca). His book, Pandora's Picnic Basket:

The Potential and Hazards of Genetically Modified Foods, was published by Oxford University Press in 2000. establish priority. Any laboratory supervisor having trouble convincing workers to keep detailed logbooks (minus personal grocery lists and doodles) will assign First Fruit as required reading.

Many readers will want to know why Flavr Savr failed, but Martineau begs the question. She emphasizes that it was not due to any reluctance on the part of consumers to eat the genetically engineered fruit. Indeed, she notes, from the initial rollout, demand exceeded supply, even with the premium-priced tomatoes well marked as genetically engineered. Benefiting from the clear vision of hindsight, Martineau does provide many examples of mismanagement, both on the commercial and, less frequently, the technical side. No doubt these contributed to the ultimate demise. But the major reason, apparent to many in the plant breeding and food production industry, was missed.

Flavr Savr failed because Calgene management lost sight of the objective; they chose their product based on technical and regulatory expediency, not on developing and marketing a superior product. Too bad they didn't include tomato breeders and production experts in their decision-making and production processes. They might have learned, for example, that Calgene need not have discarded all the good tomatoes carrying multiple inserts, as breeders can (and usually do) deal with several genes and loci at a time. Yes, it entails a bit more work, both in the field and at the regulatory agencies, but the effort might have provided a better, more market-viable tomato. By excluding all tomatoes not fitting the simplest genetic model, Calgene might have been throwing away the best parts. Nevertheless, Martineau provides an inside view of the sometimes-infelicitous decisions of Calgene's management.

Because this is not a science book, Martineau's story of the technical development of the new genetically engineered tomato is necessarily superficial. Many in the scientific community were, and remain, curious about the more general effects of antisense polygalacturonase in tomato. Does it really prolong shelf-life (and thus provide consumer appeal)? Does it maintain fruit firmness beyond the ripening point (thus facilitating harvest and distribution)? Does it really maintain vine-ripe flavor? Unfortunately, Calgene did not generate enough antisense polygalacturonase tomatoes of enough different genotypes to conduct the requisite measurements to fully answer these questions. The explanations of genetic transformation, antisense technology, and other scientific aspects are too scant to satisfy scientists or interested nonscientists, and yet not so detailed as to scare off those readers more interested in the other stories. Those expecting a full description of the technology behind Flavr Savr will be disappointed. Fortunately, a full set of footnotes and references provides the means to track down many of the details for those so inclined. The comprehensive citations also dispel the common misconception that technical documentation and data on genetically modified products are unavailable.

The most novel and moving story, however, is the personal account of an idealistic young scientist hired into a small, energetic startup company, intent on using modern science to derive useful knowledge and products. Reality sets in gradually, as the inevitable winner in the conflicts between science to derive knowledge versus science to derive a commercial product becomes more and more apparent. Martineau shares with us the frustrations of being reassigned from working on a scientifically interesting project to one conducted solely to meet regulatory compliance or commercially expedient goals.

An important contribution is Martineau's treatment of scientists as human beings. The frequent popular image of a scientist, especially a corporate scientist, is of a two-dimensional faceless boffin, perhaps brilliant at conducting experiments in an ivory tower or secret commercial laboratory, but too naive to realize the results are being coerced to conform to a corporate agenda. Martineau effectively paints her colleagues as people who party, support football teams, coach their kids' soccer teams, and argue politics in addition to conducting science. Of course, she has her biases, but she's entitled to them; this is her book and her perspective.

Perhaps this will inspire other scientists, both corporate and academic, to take the time to document, for a nontechnical audience, their own perspectives and experiences, good and bad. Perhaps then society will shift its stereotypic view of scientists to one showing us to be humans after all. 